\title{
Effect of Muscles Stretching Exercises on Severity of Restless Legs Syndrome of Adult Patients Undergoing Hemodialysis
}

\author{
Azza Awad Algendy ${ }^{1 \& 2} \&$ ZeinabFaried Bahgat ${ }^{3}$ \\ 1. Lecturer, Critical Care Nursing Department; College of Nursing, Cairo University, ARE \\ 2. Assistant Professor, King Saud Bin Abdulaziz University for Health Science, College of Nursing, KSA \\ 3. Lecturer, Medical Surgical Nursing Department; College of Nursing, Tanta University, ARE
}

\begin{abstract}
:
The patients undergoing hemodialysis usually have several complications including restless leg syndrome, which is a neurological disorder characterized by uncomfortable sensation of paraesthesia in legs that subsequently causes involuntary and continuous movement of the lower limbs especially in night which can lead to; sleep disorder, anxiety, fatigue, depression, disturbance of ability to work and social isolation. Moderate exercise may be helpful in relieving restless leg syndrome. The aim of the study is to assess the effect of muscles stretching exercises on severity of restless legs syndrome of adult patients undergoing hemodialysis. A quasi-experimental design was utilized. Sample: 40 convenience adult patients diagnosed with renal failure and undergoing hemodialysis. Settings; Hemodialysis department in the Students Hospital Affiliated to Tanta University and Elmabra Hospital for Health Insurance. Data collection: Structured interview used to elicit data which comprises two tools; Tool 1: Health assessment tool which include Bio- Socio-demographic characteristics data; Tool 2: International Restless Legs Syndrome Rating Scale (IRLSRS). Data was collected through three phases; Assessment, implementation and evaluation phase through 20 weeks. Results: Indicated improvement of severity of restless leg syndrome symptoms of the study group post comparing to pre muscle stretching exercise. Conclusion: muscles stretching exercise plays an important role in reducing the severity of RLS symptoms of adult patients undergoing hemodialysis. Recommendation: Nurses has to be encouraged to help alleviate the severity of RLS symptoms by training muscle stretching exercises to the patients undergoing heamodialysis.
\end{abstract}

Key wards: Muscle Stretching Exercises, Restless Legs Syndrome, Hemodialysis

DOI: $10.7176 / \mathrm{JHMN} / 68-10$

Publication date: November 30th 2019

\section{Introduction:}

Patients with end stage renal diseases required substitute treatments to survive. Hemodialysis is one of the most widespread and effective treatments for those patients estimated as over 2 million worldwide. The patients undergoing hemodialysis usually have numerous complications which result from either the end stage of renal disease or the type of treatment. One of these complications is restless leg syndrome (RLS) that is accompanied with sensory and motor disorders of limbs, especially legs, (Shahgholian, Jazi, Karimian, \&Valiani2016).

Torres, Sifuentes, Teran, Martinez, Luevanos and Bellmann 2018 reported that; RLS has regularly been reported as a complication of end-stage renal disease, particularly among patients undergoing hemodialysis. In addition, it is more common in chronic kidney disease patients than in the general population, but it is often diagnosed late and its predictors are unknown. RLS affects patients with chronic hemodialysis with about 4 times the incidence of that in the general population, (Keller 2010). The prevalence of RLS in the general population is approximately 5 to $10 \%$ of adults, while can be increased to $70 \%$ between patients with end-stage renal disease (ESRD), (Santos, Coelho, Silva, Graciolli, Dominguez, et al 2016). Although RLS is frequent among dialysis patients; it is often remains undetected because the symptoms may not be predictable as a classic clinical entity (Menezes and Andreia 2018).

RLS (also known as Willis-Ekbom disease) is a sensory-motor neurological disorder characterized by an urgent need to move the limbs, which is usually accompanied by painful sensations. This disorder mainly affects the lower body, but sometimes it can affect the upper body, (Giannaki, Hadjigeorgiou, Karatzaferi, Pantzaris, Stefanidis et al, 2013). It causes people to keep moving their legs as a result of the leg muscles creating a crawly sensation, (Kaur,Venkateasan, Kaur, Rawat, Massey,2016).

Moreover, Lin, Zhang, Qiu, Ni, Yu, et al 2019 added that RLS is a neurological disorder characterized by unpleasant sensation of paraesthesia in legs that consequently causes continuous involuntary movement of the 
lower limbs especially at rest. This happened more in the evening after sitting for a long time and the sensations are expressed in tickling, pain, itching, and stretching feelings, (Aliasgharpour, Abbasi, Razi, Kazemnezhad, 2016).

RLS causes an overpowering, irresistible need to move legs that is usually due to uncomfortable sensations that exacerbate during periods of inactivity and frequently interfere with the patient's sleep. It is often diagnosed late, especially when the symptoms are mild or nonspecific (Torres, Sifuentes, Teran, Martinez, Luevanos et al 2018). Several factors influence the severity of RLS as; hypertension, diabetes, being female, overweight and obesity, length of dialysis time, and advanced age in patients with hemodialysis. The effects of dialysis modality and adequacy on the severity of RLS are contentious, (Samavat, Fatemizadeh, Fasihi, Farrokhy, 2017).

The pathophysiology of RLS in patients with chronic kidney disease (CKD) is not well established. Authors have proposed several risk factors but the results of many studies have been inconsistent (Torres, et al 2018) .The underlying cause of RLS, however, remains to be identified. There is some support from neurophysiological studies and neuro imaging that RLS is sub-cortically generated in reticular neuron populations. Other studies show some evidence for the involvement of the dopamine and opiate systems of the central nervous system in the pathogenesis of RLS. The pathophysiological relationship between the occurrence of RLS and chronic renal failure is still ambiguous. Previous studies suggests that anemia could play a chief role in the development of uremic RLS,(Salman, 2011). Moreover; Malaki, Mortazavi, Moazemi, Shoaran, 2012 added that RLS is related to many other factors as; low serum parathyroid hormone, cardiac complications as well as presence of systemic infectious.

Worsening of the symptoms in night in patients with moderate to severe RLS leads to sleep disorder and sleep disorders. As a result, RLS patients may experience anxiety and sleep deprivation or drowsiness during the day that can disturb the daily functioning of the patient. In addition to sleep disorder; RLS causes, daily fatigue, depression, disturbance of the ability to work and social isolation. These problems lead to poor quality of life and have unfavourable effects on social activities and family life (Aliasgharpour, Abbasi, Razi, Kazemnezhad 2016).RLS symptoms contribute to impaired quality of life and people with RLS proved to have increased cardiovascular morbidity and mortality (Gopaluni, Sherif, Ahmadouk, 2016). In addition; there are an association between RLS and mental health, depression, decreased quality of life, and increased mortality and morbidity between patient undergoing haemodialysis (Samavat, Fatemizadeh, Fasihi, Farrokhy 2017).

Since the symptoms of the RLS worsen during inactivity and immobility times, these symptoms may be improved by moving. Therefore, moderate muscle exercise can be beneficial; exercises such as walking, massaging, stretching, swimming, and stationary cycle can help in relieve or decreasing of the symptoms. On the other hand; severe physical activities such as high strength sports just before sleeping time aggravate the symptoms of RLS. Daily mild exercise training can decrease or eliminate the RLS symptoms (Aliasgharpour, Abbasi, Razi, Kazemnezhad 2016). Review of recent studies showed that more researches are needed to study the effects of exercise on RLS symptoms. Stretching exercises are easily applicable by the patients and it is useful if applied on legs and doesn't affect disruption in dialysis, (Aliasgharpour, Abbasi, Razi, Kazemnezhad, 2016).

Therefore, the aim of this study is to assess effect of muscles stretching exercises on severity of restless legs syndrome of adult patients undergoing hemodialysis.

\section{Materials and method}

Design: A quasi-experimental design was utilized for the purpose of this study. Setting: The study was conducted at the hemodialysis department in the Students Hospital affiliated to Tanta University and Elmabra Hospital for Health Insurance in Almahala Elkobra, Garbia Governorate. Subjects: A convenience sample of 40 adult patients diagnosed with renal failure undergoing hemodialysis of both genders and suffering from restlessness leg syndrome. The sample size calculation based on the number of patients who are admitted in the Students Hospital and Elmabra Hospital for hemodialysis session and expected improvement of restlessness leg syndrome outcomes among the studied groups. The power analysis calculation was based on software program for the studied subjects at $95 \%$ confidence.

The 40 subjects were divided into 2 groups; control and study with 20 subjects each. The control group received the routine hospital care and the intervention group received muscle stretching exercise training. Inclusion criteria includes; adult patients, both genders, undergoing hemodialysis; have no associated diseases such as; rheumatic arthritis; neurological disorders; cancer, tuberculosis, human immune deficiency syndrome (AIDS), chronic heart diseases, liver diseases, and agree to participate in the intervention. 
Tools of data collection: Structured interview was conducted using a questionnaire developed by the researchers for the purpose of the present intervention that includes the following:

Tool 1: Health assessment tool which include two parts as follow Part A: Socio-demographic characteristics such as age, gender, marital status, educational level, working status and residence. Part B: Health relevant data; that include number of dialysis years, number of dialysis sessions per week and duration of dialysis session.

Tool 2: International Restless Legs Syndrome Rating Scale (IRLSRS):The IRLSRS was developed by the International Restless Legs Syndrome Intervention Group (IRLSIG) which adopted by the researchers and translated to Arabic Language to assess severity of a patient's RLS symptoms, The IRLSRS has been extensively used ,it was validated and found to have high levels of internal consistency, inter-examiner reliability, and testretest reliability. The questionnaire includes 10 questions where the patient is asked to rate his/ her restless leg in the last week as;4 (very severe) to 0 (none); the possible obtained total score ranging from $0-40$, and the sum of the item scores are interpreted as the following: Very severe $=31-40$, Severe $=21-30$, Moderate $=11-20$, Mild $=1-10$ and None $=0$ score. The study tools were piloted on 4 patients for feasibility and applicability before the main data collection. Reliability of the intervention questionnaire was tested and reported as Cronbach's alpha of .80 for health assessment tool and .77 for Restless Legs Syndrome Rating scale (IRLSRS).

Method of data collection: Permission to carry out the study was obtained from the authorized person from both Students and Elmabra Hospital. The researchers meet the eligible participants and explained the purpose of the study and the participants were informed that they have the right to participate in the study, and to withdraw at any time without any effect on their care given and assured that there is no harm from the study. Subjects who agreed to take a part were asked to provide written consent. The patients in control group were undergoing routine care of the hospital. For patients in the study group, the muscle stretching exercise sessions were provided and the follow up plan was arranged in time frame of pre and post muscle stretching exercise, hand out was given for exercise illustration. Ethical consideration for privacy and confidentiality of the data and results was concluded. Confidentiality and anonymity were maintained. The muscle stretching exercise sessions was conducted in three phases:

A- Assessment phase: Baseline data was collected from patients in both control and study group by using tool I part A and B and tool 2.To avoid data transmission from study to control group, data were collected first from control group over a period of 8 weeks. After reaching 20 subjects for the control group, data from the study group started. Data collection for the study group lasts for 12 weeks to be completed.

B- Implementation phase: This phase was implemented to the study group only where the researchers meet the participants after collecting the baseline data, and then plan a schedule for the muscle stretching exercise sessions. The muscle stretching exercise comprises two sessions, 30 to 45 minutes each. The first session included information about the causes of RLS and the effect and benefits of muscle stretching exercise, the second sessions contained eight muscle stretching exercises;Toe Touch, Standing Foot Grab, Kneeling Adductor Stretch, Wall Hamstring Stretch, Bench Hip Flexor Stretch, IT Band Stretch, Lateral Lunge and Half-Kneeling Calf Stretch. The muscle stretching exercise was presented in PowerPoint presentation with clear information, instructions and illustration, the contents were printed in a form of Arabic language booklet and provided to the participants. The participants were encouraged to perform the muscle stretching exercise twice daily; morning and afternoon for 30 minutes each as tolerated.

C- Evaluation phase: This phase was implemented for both groups using tool 2 one month post-performing the muscle stretching exercise.

\section{Results:}

Table (1): Percent distribution of the studied patients according to their Bio socio-demographic characteristics

This table reveals that more than half (55\%) of the control group and half $(50 \%)$ of the study group were in age group of $40-<50$ years, and $30-<40$ respectively. As for the gender, more than half $(60 \%)$ of the control group were female, while most $(75 \%)$ of the study group were male. In relation to occupation; most of the studied samples $(80 \%)$ and $(75 \%)$ of control and study group respectively are not working. Regarding to level of education, the table illustrates that less than half $(45 \%)$ and more than half $(55 \%)$ of control and study group respectively have technical education, while small percent $(15 \%)$ and $(10 \%)$ of them have higher education. In relation to marital status, most of the studied sample $(85 \%)$ and $(75 \%)$ of control and study group respectively were married. Regarding number of dialysis years, less than half (40\%) and half (50\%) of control and study group respectively started dialysis from one to less than three years ago. 
Table (2): Presented distribution of the intervention group according to the items of restless legs syndrome rating scale pre and post muscle stretching exercise training.

This table shows that; more than third $(40 \%)$ of study group participants had sever restless legs syndrome discomfort pre the intervention compared to none of them after one month of performing muscle stretching exercise, in addition small percent $(5 \%)$ of them experience mild leg discomfort which has been increased to about third $(35 \%)$ pre and post the training respectively. The difference between study group related to leg discomfort pre and post the intervention was statically significant where $p=0.002$. Also this table presents that about third $(35 \%)$ of the participants severely needed to move around because of RLS symptoms compared to none of them pre and post the intervention respectively; moreover, small percent $(5 \%)$ mildly needed to move around because of RLS symptoms compared to about third (35\%) pre and post the intervention respectively and the difference between study group related to needed to move around because of RLS symptoms was statically significant pre and post the intervention where $\mathrm{P}=0.003$.

In addition, this table reveals that only (5\%) of the study group had completely or almost completely relief of RLS getting from moving around which has been increased to $(35 \%)$ pre and post the intervention respectively while $(15 \%)$ of them experience slight relieve of RLS getting from moving around which has been decreased to none of them pre and post the intervention respectively with statistically difference where $P=0.020$. Also this table presents that most of the study group (95\%) had moderate sleep disturbance from RLS symptoms compared to half of them $(50 \%)$ pre and post the intervention respectively while none of the participant has mild sleep disturbance from RLS which has been increased to half $(50 \%)$ pre and post the intervention respectively and the difference was statistically significant where $\mathrm{P}=0.001$. Regarding severity of tiredness or sleepiness from RLS symptoms, this table shows that small percent $(5 \%)$ compared to more than half $(60 \%)$ of the participants rated their severity of tiredness or sleepiness from RLS symptoms as mild while small percent $(5 \%)$ compared to none of them rated their severity of tiredness or sleepiness from RLS symptoms as sever pre and post the intervention respectively with significant difference where $\mathrm{P}=0.001$. In relation to severity of RLS as a whole, this table reveals that small percent $(15 \%)$ of the participants had sever RLS as a whole compared to none of them pre and post intervention respectively, while none compared to more than third (40\%) of them have mild RLS as a whole pre and post intervention respectively and the difference was statistically significant where $\mathrm{P}=0.003$.

Moreover; same table illustrates that; about third (35\%) of the study group participants severely often get RLS symptoms which has been improved to none of them pre and post the intervention respectively and fifth $(20 \%)$ of them who rated often getting RLS symptoms as mild which has been increased to more than half (55\%) pre and post the intervention respectively with significant difference as $\mathrm{P}=0.006$. In relation to severity of RLS symptoms on an average day this table presents that less than third (30\%) of the study group had severe symptoms on an average day which has been decreased to none in the pre and post intervention respectively while fifth of them $(20 \%)$ had mild symptoms on an average day which has been increased to near third $(30 \%)$ in the pre and post intervention respectively and the difference was statically significant where $\mathrm{P}=0.029$. Moreover this table presents that $(15 \%)$ of the study group participants had very severe impact of RLS symptoms on ability to carry out a work compared to none of them pre and post the muscle stretching exercise respectively while none of the participants has mild impact of RLS symptoms on ability to carry out a work which has been increase dramatically to (40\%) pre and post the muscle stretching exercise respectively with significant difference where $\mathrm{P}=0.008$. Finally this table reveals that fifth $(20 \%)$ of the study group had very sever RLS symptoms on mood disturbance which has been decreased to none of them pre and post intervention respectively while none of them had mild RLS symptoms on mood disturbance which has been increased to fifth of them $(20 \%)$ pre and post intervention respectively and the difference was significant since $\mathrm{P}=0.017$.

Table (3): Percent distribution of the control group according to the items of restless legs syndrome rating scale throughout the study period

The table presents that small and same percent of control group (10\%) experience mild RLS discomfort in legs throughout the study period; more than third of them (35\%) has sever RLS discomfort in legs which has been increased to (40\%) throughout the study period. Regarding the need to move around because of RLS symptoms; the same table presents that same percent of the control group (10\%) and (35\%) experience mild and sever need to move around because of RLS symptoms respectively throughout the study period. As related to Relief of RLS getting from moving around, the table shows constant and same percent of relieve levels experience by the control group throughout the study period. For severity of sleep disturbance and severity of tiredness or sleepiness from RLS symptoms it was demonstrated that the percent of control group participants who experience sever level of sleep disturbance and sever tiredness or sleepiness from RLS symptom has been increased to double throughout the study period from $(15 \%)$ to $(30 \%)$ while the percentage of participants who experience moderate level of sleep 
disturbance and moderate tiredness or sleepiness from RLS symptom has been slightly decreased from (75\%) to $(60 \%)$ throughout the study period. Regarding severity of RLS as a whole; the same table denoted that none of the participant compared to small percentage $(5 \%)$ of them had very sever RLS as a whole throughout the study period while tenth of them (10\%) reported their RLS as a whole as mild which has been slightly decrease to $(5 \%)$ throughout the study period. Also; the table proved that less than half $(45 \%)$ of the control group participants who reported sever often get RLS symptoms which has been increased to half of them $(50 \%)$ throughout the study period moreover; small percentage $(5 \%)$ of them with very sever often get RLS symptoms has been doubled to $(10 \%)$ throughout the study period. For severity of RLS symptoms on average day; same and constant percentage severity levels of the group participants was reported throughout the study period. Related to the impact of RLS symptoms on ability to carry out a work; fourth of the control group participants $(25 \%)$ reported sever impact which has been increased to more than third $(35 \%)$ of them throughout the study period; in addition, the same percentage $(5 \%)$ of the participants reported very severe impact of RLS symptoms on ability to carry out a work throughout the study period. Finally the same table illustrates that small percentage $(5 \%)$ of the control group participants reported sever effect of RLS symptoms on mood disturbance which has been increased to $(25 \%)$ of them throughout the study period and majority of them (80\%) experienced moderate mood disturbance which has been decreased to more than half $(60 \%)$ of them throughout the study period. This table illustrates that there was no significant difference in the control group related to all items of RLSRS throughout the study period.

Figure I: This figure shows percentage distribution of the studied groups according to their total level of RLS severity pre and post muscle stretching exercise. It reveals high decrease in restless leg syndrome severity in the study group where $(40 \%)$ of the participants had sever total level of RLS syndrome compared to none of them in the pre and post training respectively. Moreover; all study group participants have moderate total level of RLS syndrome post intervention.

For control group; the same and small percent $(5 \%)$ of the participants continue throughout the study period as having mild and very sever total level of RLS symptoms; in addition half of the participants (50\%) have sever total RLS symptoms which has been increased to $(60 \%)$ throughout the study period.

Table (4): This table presents the relation of socio-demographic characteristics of the control group on total level of RLS severity throughout the study period. It was found that there were no significant differences in the mean scores of total level of RLS severity throughout the study period with socio characteristics data of control group except in number of years of dialysis where $\mathrm{P}=0.029$.

Table (5): This table presents the relation of socio-demographic characteristics of the study group on total level of RLS severity pre and post muscle stretching exercises. It found that there were no significant differences in the mean scores of total level of RLS severity pre and post muscle stretching exercise in the study group with their socio characteristics data.

Table (1): Percentage distribution of the studied groups according to their Bio-socio-demographic characteristics

\begin{tabular}{|c|c|c|c|c|}
\hline \multirow{3}{*}{ Characteristics } & \multicolumn{4}{|c|}{ The studied patients $(n=40)$} \\
\hline & \multicolumn{2}{|c|}{ Control group $(n=20)$} & \multicolumn{2}{|c|}{ Intervention group $(\mathrm{n}=\mathbf{2 0})$} \\
\hline & $\mathbf{N}$ & $\%$ & $\mathbf{N}$ & $\%$ \\
\hline $\begin{array}{cc}\text { Age (in years) } \\
\text { - } & (21-<30) \\
\text { - } & (30-<40) \\
\text { - } & (40-<50) \\
\text { - } & (50-60)\end{array}$ & $\begin{array}{c}2 \\
3 \\
11 \\
4\end{array}$ & $\begin{array}{l}10.0 \\
15.0 \\
55.0 \\
20.0\end{array}$ & $\begin{array}{c}1 \\
10 \\
9 \\
0\end{array}$ & $\begin{array}{c}5.0 \\
50.0 \\
45.0 \\
0.0\end{array}$ \\
\hline \begin{tabular}{|ll}
\multicolumn{2}{|c|}{ Gender } \\
- & Male \\
- & Female
\end{tabular} & $\begin{array}{c}8 \\
12\end{array}$ & $\begin{array}{l}40.0 \\
60.0\end{array}$ & $\begin{array}{c}15 \\
5\end{array}$ & $\begin{array}{l}75.0 \\
25.0\end{array}$ \\
\hline \begin{tabular}{|ll} 
Occupation \\
- & Work \\
- & Not work
\end{tabular} & $\begin{array}{c}4 \\
16\end{array}$ & $\begin{array}{l}20.0 \\
80.0\end{array}$ & $\begin{array}{c}5 \\
15\end{array}$ & $\begin{array}{l}25.0 \\
75.0\end{array}$ \\
\hline \begin{tabular}{|ll} 
Level of education \\
- & Illiterate \\
- & Basic education \\
- & Technical education \\
- & High education
\end{tabular} & $\begin{array}{l}5 \\
3 \\
9 \\
3\end{array}$ & $\begin{array}{l}25.0 \\
15.0 \\
45.0 \\
15.0\end{array}$ & $\begin{array}{c}2 \\
5 \\
11 \\
2\end{array}$ & $\begin{array}{l}10.0 \\
25.0 \\
55.0 \\
10.0\end{array}$ \\
\hline
\end{tabular}




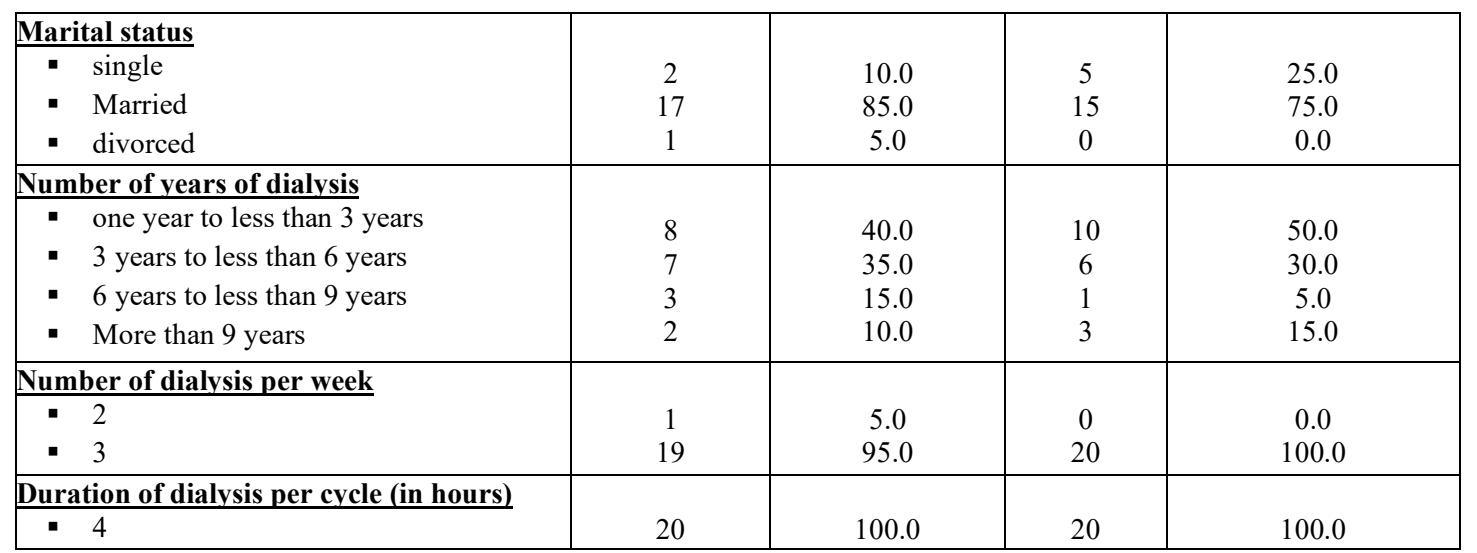

Table (2): Percentage distribution of the study group according to the items of restless legs syndrome rating scale pre and post muscle stretching exercise

\begin{tabular}{|c|c|c|c|c|c|c|}
\hline \multirow{3}{*}{\multicolumn{2}{|c|}{ Rating Scale }} & \multicolumn{4}{|c|}{ Intervention group $(\mathbf{n}=\mathbf{2 0})$} & \multirow{3}{*}{$\begin{array}{l}\chi^{2} \\
P\end{array}$} \\
\hline & & \multicolumn{2}{|c|}{ Pre } & \multicolumn{2}{|c|}{ Post 1 month } & \\
\hline & & $\mathbf{N}$ & $\%$ & $\mathbf{N}$ & $\%$ & \\
\hline & $\begin{array}{l}\text { 1. } \text { Rate the RLS discomfort in legs or arms } \\
\text { - Mild } \\
\text { - Moderate } \\
\text { - Severe } \\
\text { - Very severe }\end{array}$ & $\begin{array}{c}1 \\
11 \\
8 \\
0\end{array}$ & $\begin{array}{c}5.0 \\
55.0 \\
40.0 \\
0.0\end{array}$ & $\begin{array}{c}7 \\
13 \\
0 \\
0\end{array}$ & $\begin{array}{c}35.0 \\
65.0 \\
0.0 \\
0.0\end{array}$ & $\begin{array}{l}12.667 \\
0.002\end{array}$ \\
\hline & $\begin{array}{l}\text { 2. Rate needed to move around because of RLS symptoms } \\
\text { - Mild } \\
\text { - Moderate } \\
\text { - Severe } \\
\text { - Very severe }\end{array}$ & $\begin{array}{c}1 \\
12 \\
7 \\
0\end{array}$ & $\begin{array}{c}5.0 \\
60.0 \\
35.0 \\
0.0\end{array}$ & $\begin{array}{c}7 \\
13 \\
0 \\
0\end{array}$ & $\begin{array}{c}35.0 \\
65.0 \\
0.0 \\
0.0\end{array}$ & $\begin{array}{c}11.54 \\
0.003\end{array}$ \\
\hline 3. & $\begin{array}{l}\text { Relief of RLS getting from moving around } \\
\text { - Complete/almost complete } \\
\text { - } \text { Moderate relief } \\
\text { - Slight relief } \\
\text { - } \quad \text { No relief } \\
\end{array}$ & $\begin{array}{c}1 \\
16 \\
3 \\
0\end{array}$ & $\begin{array}{c}5.0 \\
80.0 \\
15.0 \\
0.0\end{array}$ & $\begin{array}{c}7 \\
13 \\
0 \\
0\end{array}$ & $\begin{array}{c}35.0 \\
65.0 \\
0.0 \\
0.0\end{array}$ & $\begin{array}{c}7.81 \\
0.020\end{array}$ \\
\hline 4. & $\begin{array}{l}\text { Severity of sleep disturbance from RLS symptoms } \\
\text { - Mild } \\
\text { - Moderate } \\
\text { - Severe } \\
\text { - Very severe }\end{array}$ & $\begin{array}{c}0 \\
19 \\
1 \\
0\end{array}$ & $\begin{array}{c}0.0 \\
95.0 \\
5.0 \\
0.0\end{array}$ & $\begin{array}{c}10 \\
10 \\
0 \\
0\end{array}$ & $\begin{array}{c}50.0 \\
50.0 \\
0.0 \\
0.0\end{array}$ & $\begin{array}{l}13.793 \\
0.001\end{array}$ \\
\hline 5. & $\begin{array}{l}\text { Severity of tiredness or sleepiness from RLS symptoms } \\
\text { - Mild } \\
\text { - Moderate } \\
\text { - Severe } \\
\text { - } \quad \text { Very severe }\end{array}$ & $\begin{array}{c}1 \\
18 \\
1 \\
0\end{array}$ & $\begin{array}{c}5.0 \\
90.0 \\
5.0 \\
0.0\end{array}$ & $\begin{array}{c}12 \\
8 \\
0 \\
0\end{array}$ & $\begin{array}{c}60.0 \\
40.0 \\
0.0 \\
0.0\end{array}$ & $\begin{array}{l}14.154 \\
0.001\end{array}$ \\
\hline 6. & $\begin{array}{l}\text { Severity of RLS as a whole } \\
\text { - } \text { Mild } \\
\text { - } \text { Moderate } \\
\text { - } \quad \text { Severe } \\
\text { - } \quad \text { Very severe }\end{array}$ & $\begin{array}{c}0 \\
17 \\
3 \\
0\end{array}$ & $\begin{array}{c}0.0 \\
85.0 \\
15.0 \\
0.0\end{array}$ & $\begin{array}{c}8 \\
12 \\
0 \\
0\end{array}$ & $\begin{array}{c}40.0 \\
60.0 \\
0.0 \\
0.0\end{array}$ & $\begin{array}{l}11.862 \\
0.003\end{array}$ \\
\hline 7. & $\begin{array}{l}\text { How often get RLS symptoms } \\
\text { - Mild } \\
\text { - } \quad \text { Moderate } \\
\text { - } \quad \text { Severe } \\
\text { - } \quad \text { Very severe }\end{array}$ & $\begin{array}{l}4 \\
9 \\
7 \\
0\end{array}$ & $\begin{array}{c}20.0 \\
45.0 \\
35.0 \\
0.0\end{array}$ & $\begin{array}{c}11 \\
9 \\
0 \\
0\end{array}$ & $\begin{array}{c}55.0 \\
45.0 \\
0.0 \\
0.0\end{array}$ & $\begin{array}{l}10.267 \\
0.006\end{array}$ \\
\hline
\end{tabular}




\begin{tabular}{|c|c|c|c|c|c|}
\hline $\begin{array}{l}\text { 8. Severity of RLS symptoms on an average day } \\
\text { - Mild } \\
\text { - Moderate } \\
\text { - Severe } \\
\text { - Very severe }\end{array}$ & $\begin{array}{c}4 \\
10 \\
6 \\
0\end{array}$ & $\begin{array}{c}20.0 \\
50.0 \\
30.0 \\
0.0\end{array}$ & $\begin{array}{c}6 \\
14 \\
0 \\
0\end{array}$ & $\begin{array}{c}30.0 \\
70.0 \\
0.0 \\
0.0\end{array}$ & $\begin{array}{c}7.067 \\
0.029 *\end{array}$ \\
\hline $\begin{array}{l}\text { 9. Severity of impacting RLS symptoms on ability to carry out a } \\
\text { work } \\
\text { - Mild } \\
\text { - Moderate } \\
\text { - Severe } \\
\text { - Very severe }\end{array}$ & $\begin{array}{c}0 \\
14 \\
3 \\
3\end{array}$ & $\begin{array}{c}0.0 \\
70.0 \\
15.0 \\
15.0\end{array}$ & $\begin{array}{c}8 \\
10 \\
2 \\
0\end{array}$ & $\begin{array}{c}40.0 \\
50.0 \\
10.0 \\
0.0\end{array}$ & $\begin{array}{l}11.867 \\
0.008^{*}\end{array}$ \\
\hline $\begin{array}{l}\text { 10. How severe are your RLS symptoms on mood disturbance } \\
\text { - Mild } \\
\text { - Moderate } \\
\text { - Severe } \\
\text { - Very severe }\end{array}$ & $\begin{array}{c}0 \\
15 \\
1 \\
4\end{array}$ & $\begin{array}{c}0.0 \\
75.0 \\
5.0 \\
20.0\end{array}$ & $\begin{array}{c}4 \\
12 \\
4 \\
0\end{array}$ & $\begin{array}{c}20.0 \\
60.0 \\
20.0 \\
0.0\end{array}$ & $\begin{array}{l}10.133 \\
0.017^{*}\end{array}$ \\
\hline
\end{tabular}

* Significant at level $\mathrm{P}<0.05$.

Table (3): Percentage distribution of the control group according to the items of restless legs syndrome rating scale throughout the study period

\begin{tabular}{|c|c|c|c|c|c|}
\hline \multirow[b]{3}{*}{ Rating Scale } & \multicolumn{4}{|c|}{\begin{tabular}{|l|} 
Control group $(n=20)$ \\
\end{tabular}} & \multirow{3}{*}{$\begin{array}{l}\chi^{2} \\
\mathbf{P}\end{array}$} \\
\hline & \multicolumn{2}{|c|}{ Base line } & \multicolumn{2}{|c|}{1 month later } & \\
\hline & $\mathbf{N}$ & $\%$ & $\mathbf{N}$ & $\%$ & \\
\hline $\begin{array}{l}\text { 1. Rate the RLS discomfort in legs or arms } \\
\text { - Mild } \\
\text { - Moderate } \\
\text { - Severe } \\
\text { - Very severe }\end{array}$ & \begin{tabular}{|c}
2 \\
11 \\
7 \\
0
\end{tabular} & $\begin{array}{c}10.0 \\
55.0 \\
35.0 \\
0.0\end{array}$ & $\begin{array}{l}2 \\
9 \\
8 \\
1\end{array}$ & $\begin{array}{c}10.0 \\
45.0 \\
40.0 \\
5.0\end{array}$ & $\begin{array}{l}1.267 \\
0.737\end{array}$ \\
\hline $\begin{array}{l}\text { 2. Rate need to move around because of RLS symptoms } \\
\text { - Mild } \\
\text { - Moderate } \\
\text { - Severe } \\
\text { - Very severe }\end{array}$ & \begin{tabular}{|c}
2 \\
11 \\
7 \\
0
\end{tabular} & $\begin{array}{c}10.0 \\
55.0 \\
35.0 \\
0.0\end{array}$ & $\begin{array}{l}2 \\
9 \\
7 \\
2\end{array}$ & $\begin{array}{l}10.0 \\
45.0 \\
35.0 \\
10.0\end{array}$ & $\begin{array}{c}2.20 \\
0.532\end{array}$ \\
\hline $\begin{array}{l}\text { 3. Relief of RLS getting from moving around } \\
\text { - Complete/almost complete } \\
\text { - Moderate relief } \\
\text { - Slight relief } \\
\text { - No relief } \\
\end{array}$ & \begin{tabular}{|c}
3 \\
15 \\
1 \\
1
\end{tabular} & $\begin{array}{c}15.0 \\
75.0 \\
5.0 \\
5.0\end{array}$ & \begin{tabular}{|c}
3 \\
15 \\
1 \\
1
\end{tabular} & $\begin{array}{c}15.0 \\
75.0 \\
5.0 \\
5.0\end{array}$ & $\begin{array}{l}0.00 \\
1.00\end{array}$ \\
\hline $\begin{array}{l}\text { 4. Severity of sleep disturbance from RLS symptoms } \\
\text { - Mild } \\
\text { - Moderate } \\
\text { - Severe } \\
\text { - Very severe }\end{array}$ & \begin{tabular}{|c}
1 \\
15 \\
3 \\
1
\end{tabular} & $\begin{array}{c}5.0 \\
75.0 \\
15.0 \\
5.0\end{array}$ & $\begin{array}{c}1 \\
12 \\
6 \\
1\end{array}$ & $\begin{array}{c}5.0 \\
60.0 \\
30.0 \\
5.0\end{array}$ & $\begin{array}{l}1.333 \\
0.721\end{array}$ \\
\hline $\begin{array}{l}\text { 5. Severity of tiredness or sleepiness from RLS symptoms } \\
\text { - Mild } \\
\text { - Moderate } \\
\text { - Severe } \\
\text { - Very severe }\end{array}$ & \begin{tabular}{|c}
1 \\
15 \\
3 \\
1
\end{tabular} & $\begin{array}{c}5.0 \\
75.0 \\
15.0 \\
5.0\end{array}$ & $\begin{array}{c}1 \\
12 \\
6 \\
1\end{array}$ & $\begin{array}{c}5.0 \\
60.0 \\
30.0 \\
5.0\end{array}$ & $\begin{array}{l}1.333 \\
0.721\end{array}$ \\
\hline $\begin{array}{l}\text { 6. Severity of RLS as a whole } \\
\text { - Mild } \\
\text { - Moderate } \\
\text { - Severe } \\
\text { - Very severe }\end{array}$ & $\begin{array}{c}2 \\
16 \\
2 \\
0\end{array}$ & $\begin{array}{c}10.0 \\
80.0 \\
10.0 \\
0.0\end{array}$ & $\begin{array}{c}1 \\
16 \\
2 \\
1\end{array}$ & $\begin{array}{c}5.0 \\
80.0 \\
10.0 \\
5.0\end{array}$ & $\begin{array}{l}1.333 \\
0.721\end{array}$ \\
\hline
\end{tabular}




\begin{tabular}{|l|c|c|c|c|c|}
\hline 7. How often get RLS symptoms & & & & & \\
- Mild & 1 & 5.0 & 1 & 5.0 & \\
- Moderate & 9 & 45.0 & 7 & 35.0 & 0.636 \\
- Severe & 9 & 45.0 & 10 & 50.0 & 0.888 \\
- Very severe & 1 & 5.0 & 2 & 10.0 & \\
\hline 8. Severity of RLS symptoms on an average day & & & & & \\
- Mild & 2 & 10.0 & 2 & 10.0 & \\
- Moderate & 9 & 45.0 & 9 & 45.0 & 0.00 \\
- Severe & 7 & 35.0 & 7 & 35.0 & 1.00 \\
- Very severe & 2 & 10.0 & 2 & 10.0 & \\
\hline 9everity of impacting RLS symptoms on ability to carry out a work & & & & & \\
- Mild & 2 & 10.0 & 2 & 10.0 & \\
- Moderate & 12 & 60.0 & 10 & 50.0 & 0.515 \\
- Severe & 5 & 25.0 & 7 & 35.0 & 0.916 \\
- Very severe & 1 & 5.0 & 1 & 5.0 & \\
\hline 10. How severe are your RLS symptoms on mood disturbance & & & & & \\
- Mild & 2 & 10.0 & 2 & 10.0 & 3.238 \\
- Moderate & 16 & 80.0 & 12 & 60.0 & 0.356 \\
- Severe & 1 & 5.0 & 5 & 25.0 & \\
- Very severe & 1 & 5.0 & 1 & 5.0 & \\
\hline
\end{tabular}

* Significant at level $\mathrm{P}<0.05$.

Figure (1): Percentage distribution of the studied groups according to their total level of RLS severity throughout the study period

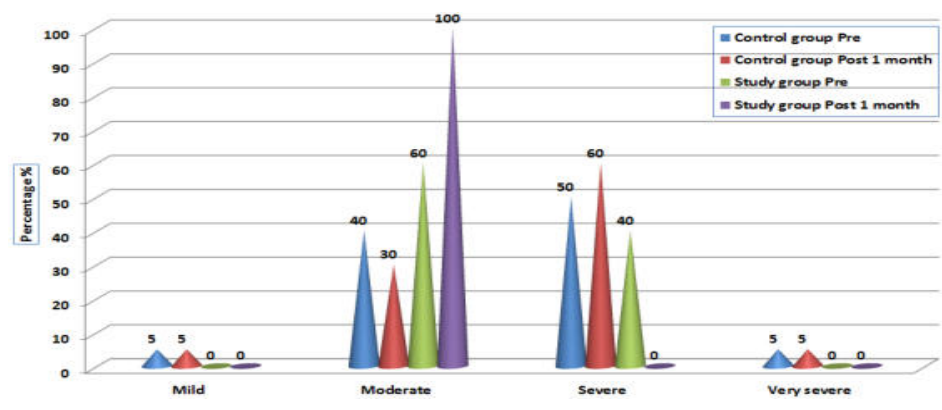


Table (4): Relation of bio-socio-demographic characteristics of the control group on total level of RLS severity throughout the study period

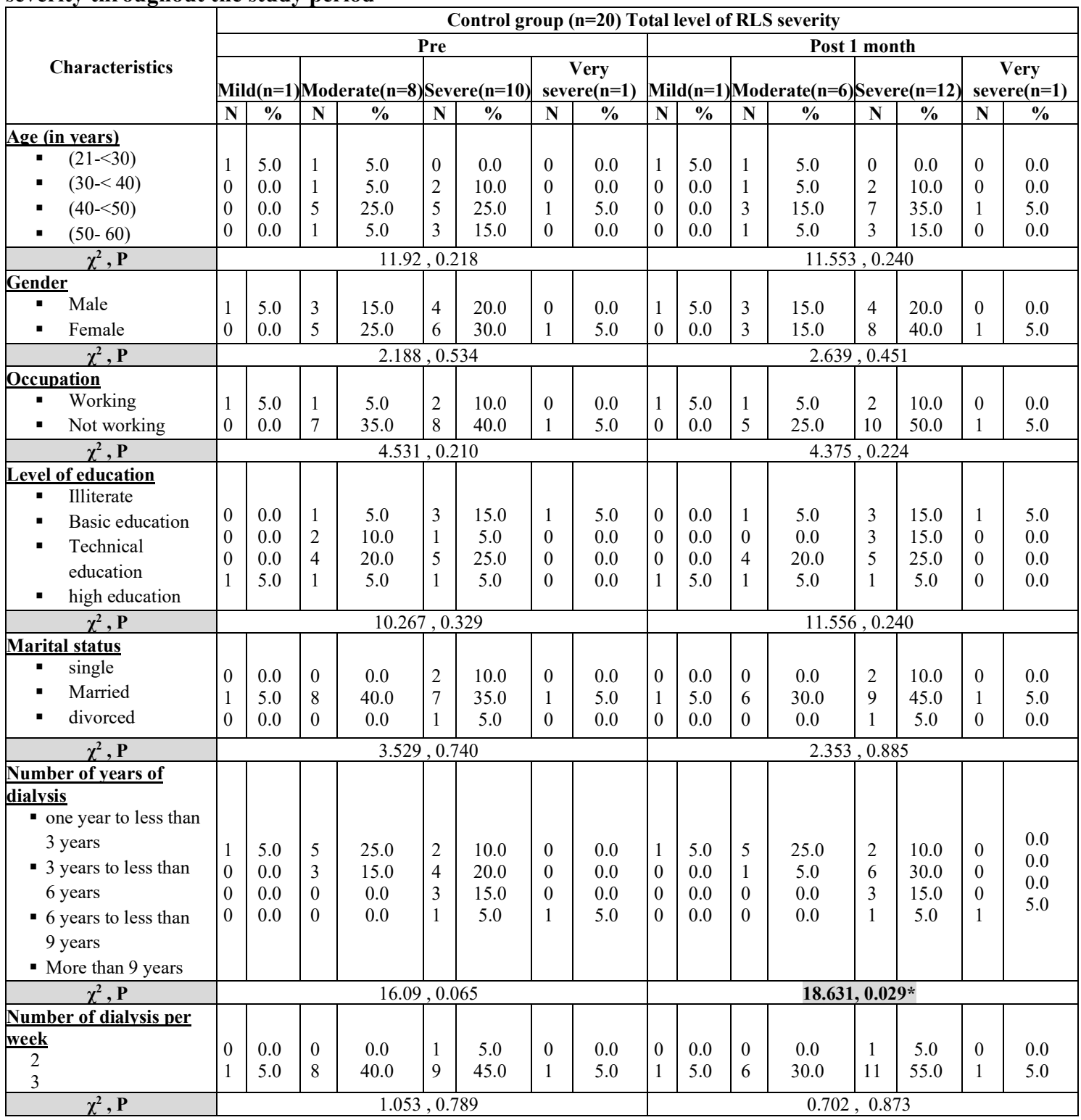

* Significant at level $\mathrm{P}<0.05$. 
Table (5): Relation of bio-socio-demographic characteristics of the study group on total level of RLS severity pre and post muscle stretching exercise

\begin{tabular}{|c|c|c|c|c|c|c|}
\hline \multirow{4}{*}{ Characteristics } & \multicolumn{6}{|c|}{ Intervention group (n=20)Total level of RLS severity } \\
\hline & \multicolumn{4}{|c|}{ Pre } & \multirow{2}{*}{\multicolumn{2}{|c|}{$\begin{array}{c}\text { Post } 1 \text { month } \\
\text { Moderate }(n=20)\end{array}$}} \\
\hline & \multicolumn{2}{|c|}{ Moderate(n=12) } & \multicolumn{2}{|c|}{ Severe $(n=8)$} & & \\
\hline & $\mathbf{N}$ & $\%$ & $\mathbf{N}$ & $\%$ & $\mathbf{N}$ & $\%$ \\
\hline \multicolumn{7}{|l|}{ Age (in years) } \\
\hline - $\quad(21-<30)$ & 1 & 5.0 & 0 & 0.0 & 1 & 5.0 \\
\hline - $\quad(30-<40)$ & 7 & 35.0 & 3 & 15.0 & 10 & 50.0 \\
\hline . $\quad(40-<50)$ & 4 & 20.0 & 5 & 25.0 & 9 & 45.0 \\
\hline - $\quad(50-60)$ & 0 & 0.0 & 0 & 0.0 & 0 & 0.0 \\
\hline$\chi^{2}, \mathbf{P}$ & \multicolumn{4}{|c|}{$1.991,0.370$} & \multicolumn{2}{|c|}{ - } \\
\hline \multicolumn{7}{|l|}{ Gender } \\
\hline - Male & 8 & 40.0 & 7 & 35.0 & 15 & 75.0 \\
\hline - Female & 4 & 20.0 & 1 & 5.0 & 5 & 25.0 \\
\hline$\chi^{2}, \mathbf{P}$ & \multicolumn{4}{|c|}{ FE , 0.603} & \multicolumn{2}{|c|}{-} \\
\hline \multicolumn{7}{|l|}{ Occupation } \\
\hline - Working & 1 & 5.0 & 4 & 20.0 & & 25.0 \\
\hline - Not working & 11 & 55.0 & 4 & 20.0 & & 75.0 \\
\hline$\chi 2, \mathrm{P}$ & \multicolumn{4}{|c|}{ FE, 0.109} & & \\
\hline \multicolumn{7}{|l|}{ Level of education } \\
\hline - $\quad$ Illiterate & 0 & 0.0 & 2 & 10.0 & 2 & 10.0 \\
\hline - $\quad$ Basic education & 3 & 15.0 & 2 & 10.0 & 5 & 25.0 \\
\hline - Technical education & 7 & 35.0 & 4 & 20.0 & 11 & 55.0 \\
\hline - high education & 2 & 10.0 & 0 & 0.0 & 2 & 10.0 \\
\hline$\chi^{2}, \mathbf{P}$ & \multicolumn{4}{|c|}{$4.394,0.222$} & \multicolumn{2}{|c|}{-} \\
\hline \multicolumn{7}{|l|}{ Marital status } \\
\hline - $\quad$ Single & 4 & 20.0 & 1 & 5.0 & 5 & 25.0 \\
\hline - $\quad$ Married & 8 & 40.0 & 7 & 35.0 & 15 & 75.0 \\
\hline$\chi^{2}, \mathbf{P}$ & \multicolumn{4}{|c|}{ FE, 0.603} & \multicolumn{2}{|c|}{-} \\
\hline \multicolumn{7}{|l|}{ Number of years of dialysis } \\
\hline - $\quad$ one year to less than 3 years & 6 & 30.0 & 4 & 20.0 & 10 & 50.0 \\
\hline - 3 years to less than 6 years & 4 & 20.0 & 2 & 10.0 & 6 & 30.0 \\
\hline - 6 years to less than 9 years & 1 & 5.0 & 0 & 0.0 & 1 & 5.0 \\
\hline - More than 9 years & 1 & 5.0 & 2 & 10.0 & 3 & 15.0 \\
\hline$\chi^{2}, \mathbf{P}$ & \multicolumn{4}{|c|}{$1.667,0.644$} & \multicolumn{2}{|c|}{-} \\
\hline Number of dialysis per week & & & & & & \\
\hline 3 & 12 & 60.0 & 8 & 40.0 & 20 & 100.0 \\
\hline$\chi^{2}, \mathbf{P}$ & \multicolumn{6}{|r|}{ 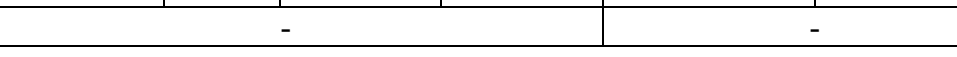 } \\
\hline
\end{tabular}

FE: Fisher' Exact test

\section{Discussion:}

The present study was conducted in an attempt to to assess effect of muscles stretching exercises on severity of restless legs syndrome of adult patients undergoing hemodialysis. The result of the present study illustrated that; half of the study sample aged from forty to fifty, more than half of them were male, about two thirds not working, half of them were have technical education, more than two thirds are married, about half undergoing hemodialysis for three years or less, almost all of them have three sessions of dialysis per week, and all of them have four hours duration of the dialysis cycle. The current study revealed that; there is a significant improvement in the Restless Legs Syndrome Rating Scale pre \& post muscle stretching exercise of the study group. It demonstrated high significant variation related to all items of RLS rating scale. While there is no significant difference in the Restless Legs Syndrome Rating Scale throughout the study period within the control group. 
Moreover, the current study proved significant difference of the study group according to their total level of RLS severity pre and post intervention. It revealed highest decrease in restless leg syndrome severity post muscle stretching exercise. In comparing to control group there was no significant difference of total level of RLS severity throughout the study period. The present study results are consistent with many other results which support the positive effect of the stretching exercises on the RLS among hemodialysis patient. Aliasgharpour, Abbasi, Razi, Kazemnezhad (2016) supported the current study result and found that the severity scores in the study group decreased after 8 weeks training of stretching exercises, and the changes were significant.

Also, Kaur, Venkateasan, Kaur, Rawat, Massey (2016) proved that in baseline data, the RLS mean score was higher which has been significantly reduced one week after muscle stretching exercise training. Shahgholian , Ghafourifard, Rafieian , \& Mortazavi 2008 reported that practicing of stretching exercises was effective than application of two methods of reflexology on decreasing the severity of restless leg syndrome among hemodialysis patients. Bastani, Ghasemi, Sadeghi (2018) support the current study results and showed that the participants who exposed to muscle stretching exercise intervention experienced a significant reduction of the RLS rating scale more than the control group. This showed that there is a positive effect of the muscle stretching exercise on decreasing of RLS scale.

In addition; Giannaki,Hadjigeorgiou, Karatzaferi ,Maridaki, Koutedakis et al. (2014) founded that; RLS severity significantly decreased in the progressive exercise training group compared to the control group. In contrast to some researchers; Samavat, Fatemizadeh, Fasihi , Farrokhy (2017) showed that moderately vigorous physical activity like high strength sports before sleeping is expressively linked to the severity of RLS symptoms. Therefore, hemodialysis patients are advised to avoid severe and vigorous sport training especially before bedtime.

The result of the present study, showed a positive results on the study group one month post muscle stretching exercise training, this result is inconsistent with Zadeh, Hami, Boostani, Mojahedi (2017)who stated that significant changes in the severity of RLS symptoms are observed from start of first week to week six; adding that no significant change was detected after week six to the end of three months, therefore, exercising for two months can be adequate to prove the effectiveness of stretching exercises on the severity of RLS symptoms. In relation to; the effect of Bio-socio demographic characteristics on total level of RLS severity pre and post muscle stretching exercise, the current study denoted no significant differences in the mean scores of total levels of RLS severity throughout the study periodin the control group with their bio-socio-demographic characteristics except in number of years of dialysis. For the study group there was no significant differences found in the mean scores of total levels of RLS severity pre and post muscle stretching exercise in the control group with their bio-sociodemographic characteristics.

This results is consistent with Kaur, Venkateasan, Kaur, Rawat, Massey(2016), who revealed that; no significant association between the pre RLS rating scale score with personal characteristics as sex, age, type of family, level of education, marital status, occupation, religion, frequency of dialysis per week, and duration of dialysis per cycle, except income and personnel habits. Also; Lin, Zhang, Qiu, Ni , Yu , Ku , Ondo , Yu and Wu (2019) found no meaningful association between RLS and the period of hemodialysis. The present results also supported by (Salman, 2011), who concluded that; RLS wasn't significantly correlated to age, and there was no significant difference in sex or duration of dialysis between the study participants.

In contrast; Giannaki, Hadjigeorgiou, Karatzaferi, Pantzaris, Stefanidis \&Sakkas (2014), in evidence-based review about epidemiology, impact, and treatment options of restless legs syndrome in end-stage renal disease patients, stated that; numerous factors affecting RLS status and severity of RLS which include; hypertension, sex, obesity, and years of dialysis. In addition; age and co-morbidity as diabetes mellitus were associated with severity of RLS symptoms. Also this study is contradicting with Lin, Zhang, Qiu, Ni , Yu, Ku, Ondo , Yu and Wu (2019), who reported that RLS is more frequent in female gender with end stage renal disease; so the correlation between biosocio-demographic characteristics still contentious.

\section{Conclusion:}

This study revealed that muscles stretching exercise plays an important role in reducing the severity of RLS symptoms of adult patients undergoing haemodialysis. Nurses should acquire comprehensive knowledge related to restless leg syndrome and should have extensive information regarding the importance of muscles stretching exercise in reducing the severity of RLS among adult patients undergoing haemodialysis patient. 


\section{Recommendations:}

1. Conducting further similar studies in different hemodialysis units in Egypt with larger number of participants to widely assess the effectiveness of muscle stretching exercise on the severity of restless leg syndrome among patients on haemodialysis.

2. Nurses can help alleviate the severity of RLS symptoms by training the patients undergoing heamodialysis the muscle stretching exercises.

\section{References:}

Aliasgharpour M., Abbasi Z.,Razi, P \&Kazemnezhad A. 2016. The effect of stretching exercises on severity of restless legs syndrome in patients on hemodialysis. Asian J Sports Med. 7 (2). doi: 10.5812/asjsm.31001.

Bastani M, Ghasemi G, Sadeghi M. The effect of selected core stability exercises on restless legs syndrome and quality of life in the elderly undergoing hemodialysis. Qom Univ Med Sci J 2018;12(8):48-58.

Beladi S, Jafarizade M, Shayanpour S, Bahadoram M, Moosavian M, et al. Restless Legs Syndrome: Associated Risk Factors in Hemodialysis Patients, Nephro-Urol Mon. 2015 ; 7(6):e31967.

Giannaki D, Hadjigeorgiou M, Karatzaferi C, Pantzaris C, Stefanidis I, Sakkas K, Epidemiology, impact, and treatment options of restless legs syndrome in end-stage renal disease patients: an evidence-based review, Kidney Int. 2014 Jun;85(6):1275-82. Epub 2013 Oct 09.

Gopaluni S, Sherif M, Ahmadouk N. Interventions for chronic kidney disease-associated restless legs syndrome. Cochrane Database Syst Rev. 2016;11(11):CD010690. Published 2016 Nov 7. doi:10.1002/14651858.CD010690.pub2.

Kaur J., Venkateasan M., Kaur K., Rawat S., Massey H. 2016. Effectiveness of muscle stretching exercise on quality of life of haemodialysis patients. International Journal of Medical Research \& Health Sciences, 5, 4:203207. ISSN No: 2319-5886

Keller M., Restless Legs Syndrome More Prevalent Among Hemodialysis Patients, Correlates With CRP Levels - Medscape - Jul 02, 2010.

Lin X., Zhang J, Qiu M, Ni L, Yu H, Ku S, Ondo W, Yu Q and Wu Y. 2019. Restless legs syndrome in end stage renaldisease patients undergoing hemodialysis. MC Neurology 19:47 https://doi.org/10.1186/s12883-019-1265-y.

Malaki M., Mortazavi S., Moazemi A, and Shoaran M., "Insomnia and limb pain in hemodialysis patients: what is the share of restless leg syndrome?" Saudi Journal of Kidney Diseases and Transplantation, vol. 23, no. 1, pp. $15-20,2012$.

Menezes M and Andreia A "Restless Legs Syndrome in Dialysis Patients: Does the Dialysis Modality Influence Its Occurrence and Severity?.” International journal of nephrology vol. 2018 1414568. 25 Feb. 2018, doi: $10.1155 / 2018 / 1414568$

Mortazavi S, Mojgan A . "Aerobic exercise improves signs of restless leg syndrome in end stage renal disease patients suffering chronic hemodialysis." TheScientificWorldJournal vol. 2013628142.6 Nov. 2013, doi:10.1155/2013/628142.

Novak M., Winkelman W., Unruh M., Restless Legs Syndrome in Patients with Chronic Kidney Disease, (2015) Seminars in Nephrology, 35 (4), pp. 347-358.

Salman M., 2011 "Restless legs syndrome in patients on hemodialysis," American Journal of Kidney Diseases, vol. 22, pp. 368-372, 2011.

Samavat S, Fatemizadeh S, Fasihi H, Farrokhy M. Restless Leg Syndrome, Insomnia, and Depression in Hemodialysis Patients: Three Sides of a Triangle?, Nephro-Urol Mon. 2017 ; 9(3):e45076. doi: 10.5812/numonthly.45076.

Santos S, Coelho M, Silva C, Graciolli G, Dominguez V, Menezes L, Jorgetti V, Moyses M, Elias M. Parathyroidectomy improves restless leg syndrome in patients on hemodialysis. PLoS One. 2016;11(5):e0155835. 
Shahgholian N., Ghafourifard M., Rafieian M., \& Mortazavi M. 2008. Impact of two types of sodium and ultrafiltration profiles on intradialytic hypotension in hemodialysis patients. IJNMR Autumn. 13, 135-136.

The International Restless Legs Syndrome InterventionGroup.Validation of the International Restless Legs Syndrome InterventionGroup.Rating Scale for Restless Legs Syndrome.Sleep Med. 2003; 4 (2):121-132.

Torres A., Sifuentes I., Teran S., Martinez S., Luevanos C., Bellmann E., Restless legs syndrome in end-stage renal disease patients undergoing hemodialysis, 2018, Arq. Neuro-Psiquiatr.vol.76 no.12 Sao Paulo Dec. 2018, http://dx.doi.org/10.1590/0004-282x20180133.

Zadeh N, Hami M, Boostani R, Mojahedi J. Restless leg syndrome in chronic hemodialysis patients in Mashhad hemodialysis centers. J Renal Inj Prev. 2017;6(2):137-141. DOI: 10.15171/jrip.2017.27. 